\section{Perfil das vítimas de trauma por acidente de moto atendidas em um serviço público de emergência}

\author{
Profile of motorcycle accident victims treated \\ at a public hospital emergency department
}

\begin{abstract}
The number of accidents involving motorcycles has increased in Brazil. The objective of this study was to identify the type of victims of these accidents who were treated at an emergency department in Piaui State, Brazil. The sample included 430 such victims in this quantitative study. Most were male, 15-24 years of age, and from the State of Piaui itself. 301 of the victims were drivers of the motorcycles, 81 were passengers, and 48 were struck or run over by the motorcycles. $76.05 \%$ of the accidents occurred from Thursday to Sunday. 80.75\% had temporary sequelae, and $53.33 \%$ of the accidents occurred at night. In $69.3 \%$ of the cases, victims suffered lacerations; $51.4 \%$ fractures; $27.44 \%$ hematomas; and $20.7 \%$ head trauma. Among the accident victims, motorcycle drivers, and those suspected of alcohol consumption, $52.07 \%$ were not wearing a helmet at the time of the accident. Most of the victims were discharged from hospital, while 14 died. In conclusion, injuries from motorcycle accidents deserve attention, especially to plan preventive measures to help control their occurrence in the State.
\end{abstract}

Traffic Accidents; Motorcycles; Emergency Medical Services

\author{
Ana Maria Ribeiro dos Santos 1,2 \\ Maria Eliete Batista Moura 1,2 \\ Benevina Maria Vilar Teixeira Nunes 1,2 \\ Clara Francisca dos Santos Leal 1,3 \\ João Batista Mendes Teles 1,2
}

\section{Introdução}

A partir da década de 1980, as causas externas passaram a representar a segunda causa de morte no Brasil e a primeira para aqueles que se encontram entre 5 e 39 anos. Nesse contexto, variados estudos epidemiológicos publicados caracterizam as causas externas e suas vítimas sob os mais diferentes aspectos, enfatizando a violência que resulta em danos quantificáveis que matam e lesam as pessoas ${ }^{1}$.

Embora não haja dúvida de que a violência e os acidentes constituam problemas que afetam a saúde, ao longo do tempo, no Brasil, eles vêm sendo tratados como objeto exclusivo da segurança pública, e somente a partir de 1993 foi que o setor saúde passou a assumi-los oficialmente.

Em 1998, o Ministério da Saúde criou um comitê técnico com a finalidade de diagnosticar e propor ações específicas para o setor, tendo em vista que o perfil de mortalidade e de morbidade da população brasileira é marcado bem mais pelas condições, situações e estilos de vida do que pelas enfermidades tradicionais, sendo que a violência e os acidentes merecem tanta atenção como a AIDS, o câncer e as enfermidades cardiovasculares 2 .

Desse modo, foi promulgada, em 2001, a Política Nacional de Redução de Acidentes e Violências. Para sua implementação, a Secretaria de Vigilância em Saúde do Ministério da Saúde estruturou, em 2004, a Rede Nacional de Prevenção 
de Acidentes e Violências. Por sua vez, foi então aprovada, em 2005, a Agenda Nacional de Vigilância, Prevenção e Controle dos Acidentes e Violências ${ }^{3}$.

Os dados de mortalidade no país, em 2002, mostram que, dos 982.807 óbitos registrados no sistema, 126.550 (12,87\%) foram devido às causas externas; deste total, 33.288 corresponderam a acidentes de transporte (3,38\% do total de óbitos e $26,30 \%$ das causas externas) (Departamento de Informática do SUS; http://www.datasus.gov.br, acessado em 28/Mar/2005). Os dados evidenciam a demanda significativa que representam as causas externas para os serviços de emergência e a importante carga social que denotam, não só pelas seqüelas e perda de vidas, como também por onerarem a sociedade com os custos diretos e indiretos.

Assinale-se que, na última década, dentre os acidentes de trânsito, vem-se observando o aumento crescente do número de acidentes envolvendo motocicletas, veículo que ganha cada vez mais a aceitação e aprovação da população, por ser ágil e de custo reduzido 4.

No Brasil, em 1997, entre 40 mil acidentes com veículos de duas rodas, aconteceram 24 mil mortes 5, e os dados de internação por grupos de causas identificam que, em 1998, foram internados 15.232 motociclistas, vítimas de acidentes de transporte, sendo que, em 2004, este número evoluiu para 27.388, ocorrendo, portanto, um aumento de 79,8\% (Departamento de Informática do SUS; http://www.datasus.gov.br, acessado em 28/Mar/2005). Os dados relativos ao Estado do Piauí evidenciam que, em 1998, 250 motociclistas foram vítimas de acidentes de transporte, sendo que este número subiu para 1.203 casos em 2004, correspondendo ao aumento de $381,2 \% 6$.

No cotidiano do serviço público de emergência, no Piauí, tem-se observado também o aumento de acidentes envolvendo motociclistas. Por isso, esta pesquisa teve como objetivo caracterizar as vítimas de trauma por acidente de motos atendidas nesse serviço.

\section{Metodologia}

A pesquisa foi de natureza descritiva, com abordagem quantitativa, desenvolvida em um serviço de emergência situado no Município de Teresina, Piauí, fundado em 1941, localizado na zona Centro/Sul do município, o qual presta atendimento a clientes do próprio estado, além de alguns estados vizinhos, tais como: Maranhão, Pará e Tocantins.

A amostra constou de 430 vítimas de trauma por acidente de moto, atendidas no referido ser- viço, determinada por amostragem probabilística do tipo casual simples para a determinação da semana de cada mês em que ocorreu a coleta de dados. Foi realizado sorteio pela tabela de números aleatórios, quando foi escolhida, por sorte, a coluna de número 15; a partir desta, os cinco primeiros algarismos entre 1 e 4 . Dessa forma, no primeiro mês, a coleta de dados ocorreu na quarta semana; no segundo mês, na terceira; no terceiro mês, na primeira; no quarto mês ocorreu novamente na quarta e; finalmente, no quinto mês, na terceira. É importante salientar que durante essas semanas os pesquisadores permaneceram 24 horas no referido serviço, e a escolha ou seleção casual desses pacientes ocorreu à medida em que eles foram chegando ao serviço.

Os dados foram coletados junto a clientes ou familiares de vítimas de acidente de moto, atendidos na referida instituição, no período de maio a setembro de 2006, utilizando formulário previamente elaborado, constando de dados sócio-demográficos e circunstâncias do acidente, como, por exemplo, a utilização ou não de equipamentos de segurança e relação da ocorrência do evento com a suspeita do uso de álcool. Foi investigado também o padrão das lesões sofridas pelo acidentado, quais sejam: área corporal lesada, lesões e seqüelas, procedimentos cirúrgicos a que foram submetidos e condição de saída do hospital. Todos esses dados foram armazenados e analisados estatisticamente, usando-se um banco de dados computadorizado, construído com o programa SPSS (SPSS Inc., Chicago, Estados Unidos).

Os aspectos éticos e legais do estudo foram preservados mediante autorização da Comissão de Ética em Pesquisa das instituições envolvidas, possibilitando o acesso dos pesquisadores à realização da coleta de dados.

Ressalte-se, também, que os sujeitos do estudo assinaram o termo de consentimento livre e esclarecido e tiveram garantia de anonimato, conforme preconiza a Resolução $n^{o}$. 196/96 do Conselho Nacional de Saúde.

\section{Resultados}

A Tabela 1 mostra a predominância do sexo masculino, correspondendo a $85,8 \%$ das vítimas, que se situaram principalmente na faixa etária de 15 a 24 anos e de 25 a 34, com Ensinos Fundamental e Médio incompletos, renda mensal de um a dois salários mínimos; em sua maioria solteiros e procedentes do Piauí. As vítimas foram classificadas como: condutor (301), passageiro (81) e atropelado por moto (48). Em relação ao sexo, constata-se que $95 \%$ das vítimas condutores de motocicleta 
Distribuição das vítimas de acidente de moto segundo a situação do acidente por sexo, faixa etária, escolaridade, renda mensal, estado civil e procedência. Teresina, Piauí, Brasil, maio a setembro de 2006.

\begin{tabular}{|c|c|c|c|c|c|c|c|c|}
\hline & \multicolumn{2}{|c|}{ Condutor } & \multicolumn{2}{|c|}{ Passageiro } & \multicolumn{2}{|c|}{ Atropelado por moto } & \multicolumn{2}{|c|}{ Total } \\
\hline & $\mathrm{n}$ & $\%$ & $\mathrm{n}$ & $\%$ & $n$ & $\%$ & $\mathbf{n}$ & $\%$ \\
\hline \multicolumn{9}{|l|}{ Sexo } \\
\hline Masculino & 286 & 95,02 & 48 & 59,26 & 35 & 72,92 & 369 & 85,81 \\
\hline Feminino & 15 & 4,98 & 33 & 40,74 & 13 & 27,08 & 61 & 14,19 \\
\hline \multicolumn{9}{|l|}{ Faixa etária (anos) } \\
\hline $1-4$ & 0 & 0,00 & 3 & 3,70 & 1 & 2,08 & 4 & 0,93 \\
\hline $5-14$ & 1 & 0,33 & 6 & 7,41 & 5 & 10,42 & 12 & 2,79 \\
\hline $15-24$ & 113 & 37,54 & 34 & 41,98 & 8 & 16,67 & 155 & 36,05 \\
\hline $25-34$ & 111 & 36,88 & 20 & 24,69 & 7 & 14,58 & 138 & 32,09 \\
\hline $35-54$ & 70 & 23,26 & 13 & 16,05 & 14 & 29,17 & 97 & 22,56 \\
\hline 55 e + & 6 & 1,99 & 5 & 6,17 & 13 & 27,08 & 24 & 5,58 \\
\hline \multicolumn{9}{|l|}{ Escolaridade } \\
\hline 1ㅇ grau incompleto & 87 & 28,90 & 29 & 35,80 & 23 & 47,92 & 139 & 32,33 \\
\hline 1ㅇ grau completo & 67 & 22,26 & 11 & 13,58 & 5 & 10,42 & 83 & 19,30 \\
\hline 2o grau incompleto & 106 & 35,22 & 27 & 33,33 & 6 & 12,50 & 139 & 32,33 \\
\hline 2o grau completo/3o grau incompleto & 23 & 7,64 & 6 & 7,41 & 3 & 6,25 & 32 & 7,44 \\
\hline Outro & 18 & 5,98 & 8 & 9,88 & 11 & 22,92 & 37 & 8,60 \\
\hline \multicolumn{9}{|l|}{ Renda mensal (salários mínimos) } \\
\hline$<1$ & 59 & 19,60 & 20 & 24,69 & 16 & 33,33 & 95 & 22,09 \\
\hline $1-2$ & 163 & 54,15 & 41 & 50,62 & 24 & 50,00 & 228 & 53,02 \\
\hline 3 ou mais & 52 & 17,28 & 9 & 11,11 & 3 & 6,25 & 64 & 14,88 \\
\hline Sem renda & 27 & 8,97 & 11 & 13,58 & 5 & 10,42 & 43 & 10,00 \\
\hline \multicolumn{9}{|l|}{ Estado civil } \\
\hline Casado & 132 & 43,85 & 20 & 24,69 & 20 & 41,67 & 172 & 40,00 \\
\hline Solteiro & 160 & 53,16 & 52 & 64,20 & 23 & 47,92 & 235 & 54,65 \\
\hline Outro & 9 & 2,99 & 9 & 11,11 & 5 & 10,42 & 23 & 5,35 \\
\hline \multicolumn{9}{|l|}{ Procedência } \\
\hline Piauí & 237 & 78,74 & 64 & 79,01 & 36 & 75,00 & 337 & 78,37 \\
\hline Maranhão & 62 & 20,60 & 14 & 17,28 & 12 & 25,00 & 88 & 20,47 \\
\hline Outro & 2 & 0,66 & 3 & 3,70 & 0 & 0,00 & 5 & 1,16 \\
\hline Total & 301 & 100,00 & 81 & 100,00 & 48 & 100,00 & 430 & 100,00 \\
\hline
\end{tabular}

são do sexo masculino, sendo que esta proporção diminui entre atropelados $(72,9 \%)$ e passageiros (59,3\%).

Na Tabela 2, relaciona-se o antecedente de ingestão de álcool com o dia da semana e o turno de ocorrência do acidente, além do tipo de seqüela encontrada. Verifica-se que $76 \%$ das vítimas sofreram acidente de quinta-feira a domingo, que $52,3 \%$ dos acidentes ocorreram no período noturno e $80,7 \%$ das vítimas apresentaram seqüelas temporárias. Das 141 vítimas que afirmaram ter feito uso de álcool, embora sem comprovação legal, $57,4 \%$ delas o fizeram no turno da noite. Deduz-se, então, que o crescimento do número de acidentes no citado período está relacionado com o aumento do consumo de bebidas alcoólicas. Existem chances três vezes maiores de ocorrência de acidentes no final da semana entre os acidentados que tinham feito uso de álcool.

Na Tabela 3, observa-se que entre as vítimas de acidente, condutores de moto com antecedente de ingestão de álcool, 71,2\% não utilizavam capacete no momento do acidente, enquanto que entre aqueles sem antecedente de ingestão esta proporção foi de 43,3\%. Assim, observou-se uma chance quatro vezes maior de não utilização desse equipamento de segurança entre aqueles que usavam bebida alcoólica. Observa-se também que 12 dos 13 que foram a óbito estavam sem capacete no momento do acidente, verificando-se que neste grupo a chan- 
Distribuição das vítimas de acidente de moto segundo a suspeita do uso de álcool por dia da semana, turno do acidente e a existência de seqüela permanente ou temporária. Teresina, Piauí, Brasil, maio a setembro de 2006.

\begin{tabular}{|c|c|c|c|c|c|c|}
\hline & \multicolumn{6}{|c|}{ Uso de álcool } \\
\hline & \multicolumn{2}{|c|}{ Sim } & \multicolumn{2}{|c|}{ Não } & \multicolumn{2}{|c|}{ Total } \\
\hline & $\mathbf{n}$ & $\%$ & $\mathbf{n}$ & $\%$ & $\mathbf{n}$ & $\%$ \\
\hline \multicolumn{7}{|l|}{ Dia da semana * } \\
\hline $5^{a}$ a domingo & 124 & 87,94 & 203 & 70,24 & 327 & 76,05 \\
\hline $2^{a}$ a $4^{a}$ & 17 & 12,06 & 86 & 29,76 & 103 & 23,95 \\
\hline Total & 141 & 100,00 & 289 & 100,00 & 430 & 100,00 \\
\hline \multicolumn{7}{|l|}{ Turno ** } \\
\hline Noturno & 81 & 57,45 & 144 & 49,83 & 225 & 52,33 \\
\hline Diurno & 60 & 42,55 & 145 & 50,17 & 205 & 47,67 \\
\hline Total & 141 & 100,00 & 289 & 100,00 & 430 & 100,00 \\
\hline \multicolumn{7}{|c|}{ 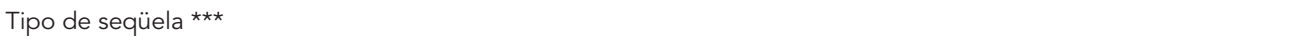 } \\
\hline Permanente & 17 & 21,79 & 24 & 17,78 & 41 & 19,25 \\
\hline Temporária & 61 & 78,21 & 111 & 82,22 & 172 & 80,75 \\
\hline Total & 78 & 100,00 & 135 & 100,00 & 213 & 100,00 \\
\hline
\end{tabular}

* OR: 3,09; IC95\%: 1,75-5,43;

** OR: 1,36 ; IC95\%: 0,91-2,04;

*** OR: 1,29; IC95\%: 0,64- 2,58.

Tabela 3

Distribuição das vítimas de acidente, condutores da moto, segundo a utilização de capacete por suspeita do uso de álcool, condição de saída, existência de traumatismo cranioencefálico e realização de procedimento cirúrgico. Teresina, Piauí, Brasil, maio a setembro de 2006 .

\begin{tabular}{|c|c|c|c|c|c|c|}
\hline & \multicolumn{6}{|c|}{ Uso de álcool } \\
\hline & \multicolumn{2}{|c|}{ Sim } & \multicolumn{2}{|c|}{ Não } & \multicolumn{2}{|c|}{ Total } \\
\hline & $\mathrm{n}$ & $\%$ & $\mathbf{n}$ & $\%$ & $\mathbf{n}$ & $\%$ \\
\hline \multicolumn{7}{|c|}{ Uso de álcool * } \\
\hline $\operatorname{Sim}$ & 88 & 52,07 & 26 & 19,70 & 114 & 37,87 \\
\hline Não & 81 & 47,93 & 106 & 80,30 & 187 & 62,13 \\
\hline Total & 169 & 100,00 & 132 & 100,00 & 301 & 100,00 \\
\hline \multicolumn{7}{|c|}{ Condições de saída ** } \\
\hline Óbito & 12 & 7,10 & 1 & 0,76 & 13 & 4,32 \\
\hline Não óbito & 157 & 92,90 & 131 & 99,24 & 288 & 95,68 \\
\hline Total & 169 & 100,00 & 132 & 100,00 & 301 & 100,00 \\
\hline \multicolumn{7}{|c|}{ Existência de traumatismo } \\
\hline \multicolumn{7}{|c|}{ cranioencefálico *** } \\
\hline Sim & 40 & 23,67 & 14 & 10,61 & 54 & 17,94 \\
\hline Não & 129 & 76,33 & 118 & 89,39 & 247 & 82,06 \\
\hline Total & 169 & 100,00 & 132 & 100,00 & 301 & 100,00 \\
\hline \multicolumn{7}{|c|}{ Procedimento cirúrgico \# } \\
\hline Sim & 86 & 50,89 & 60 & 45,45 & 146 & 48,50 \\
\hline Não & 83 & 49,11 & 72 & 54,55 & 155 & 51,50 \\
\hline Total & 169 & 100,00 & 132 & 100,00 & 301 & 100,00 \\
\hline
\end{tabular}

* OR: 4,43; IC95\%: 2,62-7,50;

** OR: 10,01; IC95\%: 1,28-78,02;

*** OR: 2,61 ; IC95\%: 1,35-5,01;

\# OR: 1,24; IC95\%: 079-1,96. 
ce de morte foi dez vezes maior do que entre aqueles que utilizavam o equipamento. Entre os que não usavam capacete, $23,7 \%$ sofreram traumatismo cranioencefálico, apresentando uma chance duas vezes maior de desenvolver a lesão do que os que faziam uso de capacete. Não houve diferença significativa na realização de procedimento cirúrgico entre os que usavam capacete e os que não usavam. Saliente-se que a maioria das vítimas possuía mais de uma área corporal lesada, encontrando-se vítimas com até cinco áreas corporais lesadas (Tabela 4). Essas lesões conduziram em $49,5 \%$ dos casos a ocorrência de seqüelas temporárias ou permanentes, sendo que as áreas com maior proporção de seqüelas foram: os membros inferiores (55\%), a face $(52,2 \%)$, os membros superiores $(48,1 \%)$ e a cabeça $(47,89 \%)$.

A Tabela 5 especifica os tipos de lesão encontrados, evidenciando que $69,3 \%$ dos acidentados apresentaram ferimentos, $51,4 \%$ fraturas, $27,4 \%$ hematomas e $20,7 \%$ traumatismo cranioencefálico. Em relação à condição de saída do hospital, 403 vítimas evoluíram para a alta hospitalar. Do total de casos, 14 foram a óbito e 11 foram transferidos para outros hospitais, sendo que dois evadiram-se do serviço. Assim, verifica-se que, no geral, a proporção de óbitos é relativamente baixa. Entretanto, chama a atenção o número de vítimas com traumatismo cranioencefálico que faleceram, correspondendo a $85,71 \%$ do total dos óbitos.

\section{Discussão}

A prevenção de acidentes e violências é o meio mais importante para evitar a morbimortalidade pelas causas externas. Sob esse aspecto, as ações concentradas em nível de prevenção primária poderão cortar a cadeia em seu momento inicial 7 .

Nesse sentido, a predominância do sexo masculino nas pesquisas envolvendo acidentes de motocicleta é marcante e varia de $79 \%$ a $96 \%{ }^{8}$ e foi corroborada neste estudo (86\%). Esse predomínio masculino em acidentes de trânsito é atribuído a uma maior exposição, em decorrência de freqüentemente serem condutores de carro, possuírem habilitação e terem aprendido a dirigir com menor idade 9 .

Em relação à faixa etária, diversas pesquisas nacionais afirmam que cerca de $70 \%$ das vítimas de acidente de trânsito têm idades entre 10 e 39 anos, por conseguinte, pertencentes ao grupo de adolescentes e adultos jovens 10. Também em Teresina são os jovens os mais afetados pelos acidentes de trânsito, $74,4 \%$ dos condutores acidentados pertenciam à faixa etária de 15 a 34 anos. Assim sendo, esses dados nos levam a refletir sobre os padrões socioculturais, em relação a questões de gênero, que se perpetuam em nossa sociedade e terminam por conduzir a altas taxas de morbimortalidade em adultos jovens do sexo masculino, no auge de suas capacidades, acarretando prejuízos econômicos consideráveis à nação.

A maior mortalidade no trânsito do condutor adolescente é um fenômeno extremamente

Tabela 4

Distribuição das vítimas de acidente de moto segundo existência de seqüela por área corporal lesada. Teresina, Piauí, Brasil، maio a setembro de 2006 .

\begin{tabular}{|c|c|c|c|c|c|c|}
\hline \multirow[t]{3}{*}{ Área corporal lesada } & \multicolumn{6}{|c|}{ Existência de seqüela } \\
\hline & \multicolumn{2}{|c|}{ Sim } & \multicolumn{2}{|c|}{ Não } & \multicolumn{2}{|c|}{ Total } \\
\hline & $\mathbf{n}$ & $\%$ & $\mathbf{n}$ & $\%$ & $\mathrm{n}$ & $\%$ \\
\hline Cabeça & 91 & 47,89 & 99 & 52,11 & 190 & 100,00 \\
\hline Face & 105 & 52,24 & 96 & 47,76 & 201 & 100,00 \\
\hline Pescoço & 9 & 60,00 & 6 & 40,00 & 15 & 100,00 \\
\hline Tórax & 28 & 44,44 & 35 & 55,56 & 63 & 100,00 \\
\hline Abdômen & 18 & 75,00 & 6 & 25,00 & 24 & 100,00 \\
\hline Coluna & 4 & 66,67 & 2 & 33,33 & 6 & 100,00 \\
\hline Pelve & 4 & 40,00 & 6 & 60,00 & 10 & 100,00 \\
\hline Membros superiores & 116 & 48,13 & 125 & 51,87 & 241 & 100,00 \\
\hline Membros inferiores & 164 & 55,03 & 134 & 44,97 & 298 & 100,00 \\
\hline Total & 213 & 49,53 & 217 & 50,47 & 430 & 100,00 \\
\hline
\end{tabular}

Nota: resposta múltipla, soma maior que $100,00 \%$. 
Distribuição das vítimas de acidente de moto segundo a condição de saída e tipo de lesão sofrida. Teresina, Piauí, Brasil, maio a setembro de 2006.

\begin{tabular}{|c|c|c|c|c|c|c|c|c|c|c|}
\hline \multirow[t]{3}{*}{ Tipo de lesão } & \multicolumn{10}{|c|}{ Condição de saída } \\
\hline & \multicolumn{2}{|c|}{ Alta } & \multicolumn{2}{|c|}{ Transferência } & \multicolumn{2}{|c|}{ Óbito } & \multicolumn{2}{|c|}{ Evasão } & \multicolumn{2}{|c|}{ Total } \\
\hline & $\mathrm{n}$ & $\%$ & $\mathrm{n}$ & $\%$ & $\mathbf{n}$ & $\%$ & $\mathbf{n}$ & $\%$ & $\mathrm{n}$ & $\%$ \\
\hline Fratura & 208 & 51,61 & 5 & 45,45 & 8 & 57,14 & 0 & 0,00 & 221 & 51,40 \\
\hline Ferimento & 283 & 70,22 & 9 & 81,82 & 5 & 35,71 & 1 & 50,00 & 298 & 69,30 \\
\hline Traumatismo cranioencefálico & 70 & 17,37 & 6 & 54,55 & 12 & 85,71 & 1 & 50,00 & 89 & 20,70 \\
\hline Luxação & 75 & 18,61 & 3 & 27,27 & 2 & 14,29 & 1 & 50,00 & 81 & 18,84 \\
\hline Hematoma & 109 & 27,05 & 5 & 45,45 & 4 & 28,57 & 0 & 0,00 & 118 & 27,44 \\
\hline Contusão & 23 & 5,71 & 0 & 0,00 & 1 & 7,14 & 0 & 0,00 & 24 & 5,58 \\
\hline Esmagamento & 7 & 1,74 & 0 & 0,00 & 0 & 0,00 & 0 & 0,00 & 7 & 1,63 \\
\hline Amputação & 3 & 0,74 & 0 & 0,00 & 0 & 0,00 & 0 & 0,00 & 3 & 0,70 \\
\hline Lesão na medula & 1 & 0,25 & 0 & 0,00 & 0 & 0,00 & 0 & 0,00 & 1 & 0,23 \\
\hline Pneumotórax & 1 & 0,25 & 0 & 0,00 & 0 & 0,00 & 0 & 0,00 & 1 & 0,23 \\
\hline Hemotórax & 3 & 0,74 & 0 & 0,00 & 1 & 7,14 & 0 & 0,00 & 4 & 0,93 \\
\hline Total & 403 & 100,00 & 11 & 100,00 & 14 & 100,00 & 2 & 100,00 & 430 & 100,00 \\
\hline
\end{tabular}

Nota: resposta múltipla, soma maior que $100,00 \%$.

complexo, que pode ser explicado, em parte, pelas características próprias desta faixa etária, como, por exemplo, a imaturidade, o sentimento de onipotência, a tendência de superestimar suas capacidades, a pouca experiência, habilidade para dirigir, e comportamentos de risco. Entretanto, sugere-se uma reflexão sobre o que a sociedade põe à disposição dos jovens, isto é, modelos identificatórios e objetos de consumo que simbolizam sucesso e felicidade, compondo alternativas por meio das quais os adolescentes se construirão como sujeitos, esquecendo-se que tais modelos e objetos de consumo servirão de base e, desta forma, estarão presentes nas relações sociais e nos padrões de conduta de ação coletiva e individual 11.

Predominam as vítimas que possuem Ensinos Fundamental (32,3\%) e Médio incompleto (32,3\%), e os que apresentam renda mensal de um a dois salários mínimos (53\%). É possível que muitos desses acidentados sejam trabalhadores que utilizam o citado veículo nas propriedades rurais em que trabalham e, como estas motos não são licenciadas, eles não passam por nenhum preparo nem são submetidos a qualquer tipo de controle pelos órgãos oficiais.

Ressalte-se que o Piauí possui ainda um número significativo de pessoas com baixa escolaridade, que não conhecem perfeitamente as sinalizações de trânsito e utilizam bicicletas e motos em seus deslocamentos, sendo importante verificar a relação entre acidentes e a qualidade das vias de deslocamento, posto que, no estado, ocorre o agravante de existirem poucas ciclovias 12

Nesse sentido, a Secretaria do Trabalho e Empreendedorismo e o Departamento Estadual de Trânsito do Piauí lançaram o projeto Capacitação de Motociclistas, abrangendo o trabalho de formação na área de segurança, legislação e relações humanas, incluindo a questão da educação no trânsito para aqueles que não têm condição de fazer um bom curso, haja vista a necessidade de diminuir os acidentes com esse tipo de veículo que crescem a cada dia no estado 13 .

Constata-se, em relação ao estado civil, que os solteiros representaram a maioria atendida no serviço, e isto se atribui ao fato de a referida maioria das vítimas constituir uma população jovem, que, geralmente, busca fortes emoções, caracterizadas pela preferência por novidades e pelo desejo de arriscar-se para obtê-las 9 .

Em razão disso, a mudança de comportamento no trânsito somente será obtida valendose da informação e educação desde a infância, como também por meio de medidas mais drásticas, como, por exemplo, a aplicação e reforço das leis, além de um controle mais enérgico por parte das autoridades 14. Por sua vez, a situação de insegurança de crianças e adolescentes no trânsito requer necessário e urgente investimento em sua reorganização, bem como das áreas urbanas, na prevenção dos atropelamentos e na educação para o trânsito 15 .

Pode-se observar que $78,4 \%$ dos casos procederam do próprio estado, inferindo-se serem de- 
correntes da necessidade de atendimento urgente ou emergente em grande parte dos acidentes, em que o tempo compreendido entre o momento do trauma e o atendimento é fundamental.

Acredita-se que os 1.203 acidentes envolvendo motociclistas, em 2004, no Estado do Piauí 6 , encontram-se diretamente relacionados ao número de motocicletas circulantes, fenômeno que acontece na maior parte das cidades do país, haja vista que estes veículos vêm ganhando cada vez mais aceitação e aprovação da população 4 . Por outro lado, a relação custo/benefício na utilização desse tipo de veículo não é diferente em nossa capital, que vem se destacando economicamente no ramo de serviços.

Em relação à situação do acidente, pesquisa realizada em Maringá, Paraná, identificou os condutores do veículo, no momento do acidente, como as maiores vítimas 4 . Outros estudos também detectaram ser a maior parte das vítimas condutores dos veículos no momento do acidente e pertencerem ao sexo masculino 16,17 , fato este também observado neste trabalho. A maior proporção de vítimas desse sexo pode estar relacionada com uma maior exposição, assim como maior utilização desse tipo de veículo, o que faz com que se compreenda a alteração da proporção aqui observada ao analisar-se a situação por sexo, verificando-se que, no sexo feminino, $54,1 \%$ das vítimas eram passageiros da motocicleta, considerando-se que, em nosso meio, ainda é reduzida a presença de mulheres pilotando esse veículo.

Destaque-se que, na faixa etária entre 55 anos ou mais, o maior percentual correspondeu ao atropelamento por moto $(54,2 \%)$. Conforme estudo realizado em Londrina, Paraná, os motociclistas representam as principais vítimas de acidente de trânsito, em todos os anos, e isto coloca em risco a integridade de outros usuários das vias públicas, especialmente pedestres, que, no Brasil, representam a maioria das vítimas de óbito 10 . Logo, deduziu-se que a ocorrência de $54,2 \%$ de atropelamentos por moto na faixa etária entre 55 anos ou mais encontrada nesta pesquisa pode estar relacionada à inabilidade, imperícia e negligência de alguns motociclistas, associada à existência de deficiências de locomoção, visuais e/ou auditivas dos pedestres nesta faixa etária mais avançada.

Os órgãos gestores do trânsito das cidades brasileiras comumente sinalizam os locais para a travessia das vias sem um estudo das rotas de circulação de pedestres, não se preocupando em atender às suas necessidades. Esse fato é atribuído à amputação da cidadania e da solidariedade social, que foi sendo construída por meio de um modelo político-econômico que incentiva o in- dividualismo e torna os indivíduos mais consumidores do que cidadãos. A alienação provocada por esse processo de fragmentação do homem e do conhecimento fez com que o país chegasse a uma profunda crise de valores, na qual o respeito ao indivíduo não tem espaço e a vida vale muito pouco, sendo que os acidentes de trânsito são reflexos desta crise, transformando-se em um dos mais graves problemas que a população brasileira enfrenta em seus deslocamentos 15 .

Outro aspecto que merece destaque refere-se ao fato de se encontrar um condutor na faixa etária de 5 a 14 anos, considerando-se que, no Brasil, a idade mínima legal para a obtenção da carteira de motociclista é de 18 anos. Desse modo, além da inexperiência comum a todos os motociclistas iniciantes, o fator ilegalidade deve ser melhor considerado, cabendo aos pais ou responsáveis pelo menor a determinação de quando e em que condições ele deve começar a fazer uso da motocicleta, particularmente como seu condutor 8 . Nesse sentido, em 2002, a American Academy of Pediatrics recomendou aos pais e ao Estado a proibição do uso de tais veículos por crianças e adolescentes, principalmente em campeonatos de motocross, atividade muito popular naquele país entre os homens menores de trinta anos. Acreditam que com essa intervenção, aliada à exigência do uso de capacete, poderá reduzir ferimentos nos motociclistas 16 .

Com relação ao aumento dos acidentes envolvendo motocicletas e quanto à sua ocorrência nos finais de semana, registra-se certa unanimidade entre os pesquisadores. Os motociclistas vítimas não-fatais foram mais freqüentes às sextas-feiras e sábados, e as vítimas fatais ocorreram mais no sábado e domingo 17 . O estudo que analisou as características dos acidentes com relação ao dia da semana de sua ocorrência observou, em todos os anos, uma elevação do número de vítimas a partir da sexta-feira, com maior concentração aos sábados, relacionando tal fato com a possível ingestão de bebidas alcoólicas, mais freqüentes nestes períodos 10 . Neste estudo verificou-se que existem três vezes mais chances dos motociclistas se envolverem em acidentes entre quinta-feira e domingo, quando há aumento do consumo de álcool, do que entre segunda e quarta-feiras, quando este consumo diminui.

Com relação à alternância dos acidentes, foi registrada uma pequena elevação do número de atendimentos no horário noturno se comparado ao diurno. Deduz-se, que a maior ocorrência de acidentes noturnos é decorrente tanto do aumento do consumo de álcool quanto provocados pela redução da visibilidade e pelo cansaço ao final do dia. Estudo realizado em São Paulo mostrou que as horas do dia prevaleceram para 
os pedestres e motociclistas. Para os passageiros, prevaleceu o período da noite 17 . Verifica-se, pois, que há fatores humanos, ambientais e mecânicos implicados no risco de acidente de trânsito, posto que o cansaço e a sobrecarga de tarefas são também provocadores de falha humana 18 .

Várias pesquisas apontam uma forte relação entre a ingestão de álcool e acidentes de trânsito. A lei, a sociedade e a justiça brasileiras são excessivamente tolerantes com motoristas alcoolizados. Somente após a promulgação do Código de Trânsito Brasileiro, em fevereiro de 1998, é que se passou a vislumbrar alguma mudança nesse aspecto, que tem sido importante para a tomada de consciência do problema, mas o controle real dos infratores continua limitado, visto que a caracterização do estado de embriaguez ainda é restrita à perícia do Instituto Médico-Legal ${ }^{19}$. Trata-se de um hábito lamentável, responsável pela perda de muitas vidas, visto que o condutor alcoolizado apresenta quatro vezes mais possibilidades de não fazer uso do capacete, conforme evidenciado no estudo, incorrendo, neste caso, em duas infrações que, pelo visto, não estão sendo devidamente fiscalizadas. Para que isso ocorra, existe a necessidade de que a fiscalização se estenda ao período noturno e aos finais de semana.

A maioria dos jovens prestes a obter a carteira de habilitação apresenta tanto alguma disponibilidade para dirigir alcoolizado quanto para a utilização de alternativas seguras depois de consumir álcool, portanto há campo para medidas educativas que, associadas a normas restritivas, como, por exemplo, o aumento de fiscalização, têm boas possibilidades de alterar as graves estatísticas em relação a dirigir alcoolizado no Brasil 20. Convém destacar que, além de a nova legislação de trânsito incluir entre as infrações graves o ato de dirigir alcoolizado, mais recentemente a veiculação de propagandas, mostrando a repercussão social dos acidentes de trânsito relacionados ao consumo de bebidas, tem se contraposto à disponibilidade e diminuído o hábito de dirigir após beber 21. Por outro lado, a questão da educação no trânsito exigirá um esforço considerável de integração de vários órgãos, como: Ministério da Saúde, abrangendo o SUS; Ministério dos Transportes; Ministério da Educação; Ministério do Trabalho e Ministério da Justiça. Desse modo, serão necessárias intervenções educativas nos níveis de Ensinos Fundamental, Médio e Superior 19 .

Em relação à utilização de equipamentos de segurança, este estudo evidenciou que $39,8 \%$ das vítimas, condutores e passageiros, utilizavam apenas o capacete. E, ao serem questionadas sobre o uso, não se reportaram aos demais equipamentos, constatando-se com isto que o capace- te é considerado principal, ocorrendo de certa forma uma desvalorização dos demais. Sabe-se que a Resolução $n^{o} .203$ do Conselho de Trânsito Brasileiro, em seu art. $1^{\circ}$, diz ser obrigatório, para circular na vias públicas, o uso de capacete pelo condutor e passageiro de motocicleta ${ }^{22}$. Mas a Associação Brasileira de Motociclistas divulga uma lista com doze mandamentos para a segurança dos motociclistas nas ruas e estradas brasileiras, que contempla: capacete aprovado pelo Instituto Nacional de Metrologia, Normalização e Qualidade Industrial (INMETRO), calça e jaqueta de tecido resistente, botas ou sapatos reforçados e luvas. Solicita ainda que utilizem o protetor de pernas e a antena anticerol 23.

Assim, verificou-se que neste estudo 60,21\% dos motociclistas não utilizavam capacete, embora o seu uso seja obrigatório para todos os ocupantes da moto. Pesquisa realizada em São Paulo com o objetivo de identificar o padrão das lesões nas vítimas de acidentes de motocicleta não encontrou registros nos prontuários sobre a utilização desse equipamento de segurança, tendo observado apenas um prontuário referindo-se a não utilização do mesmo ${ }^{8}$. Outros estudos que analisaram vítimas de acidente de moto evidenciaram que 75 e $72 \%$ das vítimas não utilizavam tal equipamento, constatando nos dois casos um maior risco de desenvolver traumatismo cranioencefálico 24,25.

Pode-se constatar também que apenas 23,3\% das vítimas possuem conhecimento sobre a validade do capacete, embora a Resolução $n^{o} .203$ do Conselho Nacional de Trânsito determine, em seu art. 1o, $\$ 2$ o, que o capacete deve estar certificado por organismo acreditado pelo INMETRO, de acordo com regulamento de avaliação da conformidade por ele aprovado 22.

Pesquisa realizada em Los Angeles, Estados Unidos, demonstrou que o uso desse equipamento pode reduzir o número e a severidade dos ferimentos na cabeça e pescoço, além de evitar os traumatismos cranioencefálicos e as fraturas cervicais. Também evidenciou que os capacetes evitam a ocorrência mais elevada de ferimentos no pescoço, reforçando assim a lei que obriga o seu uso pelos motociclistas 26 . Nesta pesquisa observou-se que os motociclistas que não utilizavam capacete no momento do acidente apresentaram uma chance duas vezes maior de traumatismo cranioencefálico que os com capacete.

Torna-se indispensável a observação rigorosa da validade do equipamento para que este ofereça a proteção necessária no momento do choque. Pelo desconhecimento observado entre os usuários, há que se destacar a importância da educação no trânsito, com adoção de comportamentos preventivos, assim como a implementa- 
ção de medidas rigorosas de vigilância e a devida punição dos infratores.

Quanto à área corporal lesada, estudo que caracterizou motociclistas acidentados mostrou que, em mais da metade das vítimas, os membros representam um dos segmentos corpóreos mais atingidos, e que os membros inferiores são a região corpórea mais gravemente lesada, dado este corroborado em nosso meio, visto serem as regiões mais desprotegidas 4 .

Os membros inferiores/pelve são mais acometidos em atropelamentos e acidentes de moto, e as lesões na cabeça e pescoço encontram-se em segundo lugar, sendo o traumatismo cranioencefálico a principal causa de morte nas vítimas de trauma 27 . Com base na realidade estudada, as lesões na face e na cabeça ocuparam o terceiro e quarto lugares, respectivamente; fato de grande importância uma vez que a mortalidade verificada no traumatismo cranioencefálico é bastante elevada e a maioria dos óbitos verificados nesta pesquisa ocorreram entre aqueles que não utilizavam o capacete, confirmando ser este risco dez vezes maior entre aqueles que não fazem uso deste equipamento.

Nos Estados Unidos, no período de 2001 a 2004, nos acidentes com motos, os ferimentos em extremidades ocorreram em $61,9 \%$ dos pacientes; destes, $35,6 \%$ eram fraturas. A cabeça e o pescoço foram afetados em $16,8 \%$ dos casos, e 47,4\% envolveram lesão de órgão interno 16 .

No que diz respeito à ocorrência de seqüelas, estas foram observadas em todas as áreas corporais levantadas no estudo. Ressalte-se que, do total de $49,5 \%$ dos acidentados com seqüelas, $80,7 \%$ correspondem a seqüelas temporárias e $19,2 \%$ a permanentes. Dessa forma, e levandose em conta a faixa etária predominantemente jovem de seqüelados, deduz-se a gravidade das perdas econômicas e sociais que os acidentes de trânsito representam para a sociedade.

Destaque-se que o número de incapacitados por acidente de trânsito tem aumentado significativamente, e a explicação para este fenômeno origina-se na maior ocorrência de acidentes de trânsito entre jovens que apresentam melhores condições de saúde para sobreviver aos acidentes graves, assim como na maior velocidade dos veículos e no aumento do número de veículos pesados, além de avanços nas técnicas médicas de ressuscitação 19 .

Os estudos que investigam os principais aspectos epidemiológicos das causas externas abordam o problema sob o aspecto da mortalidade e/ou demanda aos serviços hospitalares, sendo escassas as referências à questão das seqüelas e à qualidade de vida após o evento. Porém as lesões decorrentes dos eventos traumáticos resultam, com certa freqüência, em deficiências e incapacidades temporárias ou permanentes, que interferem na capacidade de as vítimas sobreviventes cumprirem tarefas que delas são esperadas, assim como na qualidade de suas vidas 4 .

A redução no grau das seqüelas e as chances de sobrevida das vítimas aumentam com a presteza e a qualidade do atendimento prestado. Há, além disso, recomendações para que as rodovias brasileiras sejam dotadas de serviços de atendimento de emergência, oficiais ou particulares 15.

Foram identificadas como lesões mais freqüentes os ferimentos seguidos de fraturas, de hematomas cerebrais e de traumatismos cranioencefálicos. Porém é importante destacar que embora existam lesões com número de casos mais baixo em relação às anteriormente citadas, como os esmagamentos, as amputações e as lesões medulares, são de grande importância devido à gravidade das seqüelas que provocam.

Na presente investigação, grande número de vítimas possuía lesões associadas, como fraturas e traumatismos cranioencefálicos. Esses resultados encontrados corroboram com estudos que destacam os motociclistas e pedestres como as vítimas mais graves dos acidentes de trânsito 4 .

Convém salientar também que, neste estudo, $49 \%$ das vítimas foram submetidas a procedimentos cirúrgicos. Em uma análise dos custos de um mês de assistência de emergência realizada em dois hospitais municipais do Rio de Janeiro, pôde-se verificar que as cirurgias caracterizaram o elemento de custo mais importante, quando considerado o custo total de todas as vítimas da violência na amostra estudada 28 .

Embora em nossa realidade não se tenha um cálculo, de forma sistematizada, dos custos financeiros envolvidos na atenção às vítimas de acidentes por motocicletas, mas tomando-se por base ser este tipo de acidente, um dos que gera vítimas mais graves, deduz-se então o montante dos recursos gastos pelo SUS para pagamento de procedimentos cirúrgicos múltiplos e de como ele constitui custo significativo para a assistência hospitalar.

Também foram identificados os diferentes tipos de procedimentos cirúrgicos a que essas vítimas de acidente foram submetidas; alguns destes procedimentos com números significativos de ocorrências, tais como: redução de fratura, craniotomia, fixação de fratura, limpeza mecano-cirúrgica, tratamento cirúrgico de fratura e suturas simples. No total, observou-se uma predominância das cirurgias ortopédicas, assemelhando-se a estudo realizado por Koizumi 8 que verificou um predomínio de cirurgias ortopédicas dentre as operações realizadas. 
A condição de saída do hospital da vítima de acidente de moto evidencia que a grande maioria recebeu alta hospitalar, e apenas $4,3 \%$ foram a óbito, sendo assim um percentual semelhante ao observado por Koizumi 8 (4,9\%). Não devese esquecer das vítimas que falecem antes que ocorra a internação hospitalar. Ainda, neste estudo, chama a atenção a concentração de óbitos na faixa etária de 35 a 54 anos. Infere-se, então, que isso pode ser decorrente de problemas clínicos anteriores - das vítimas nessa faixa etária mais avançada - problemas estes que podem ter sido agravados pelo quadro traumático.

Estudos mostram que as mortes por acidentes e violências incidem com elevada freqüência no grupo de adolescentes e adultos jovens, e o impacto destes óbitos pode ser analisado por meio do indicador de mortalidade prematura, denominado Anos Potenciais de Vida Perdidos (APVP) 29. Por isso, torna-se importante destacar que os acidentes de trânsito são a segunda causa de APVP (10,6\%) no Brasil 30. Nesse contexto, destaca-se a importância da utilização desse indicador de mortalidade prematura para definir prioridades e chamar a atenção sobre o caráter devastador dos traumas e violências como causa de mortes em idades jovens 31 .

\section{Conclusão}

O trauma provocado por acidentes de moto merece atenção, especialmente em relação ao planejamento de ações preventivas, assim como do controle de sua ocorrência no Estado do Piauí.

Considerando o número elevado de motociclistas circulando, em sua maioria, sem utilização dos equipamentos de segurança preconizados, fica patente que algumas estratégias determinadas pela política nacional de redução da morbimortalidade por acidentes e violências precisam ser implementadas, tais como: estimular e apoiar a realização de pesquisas consideradas estratégicas, principalmente aquelas ligadas a comportamentos no trânsito, riscos de acidentes devido às condições do veículo e uso indevido dos equipamentos de segurança; articular pessoas dos setores de educação, justiça e segurança pública, visando à criação de protocolos de cooperação na prevenção destes acidentes; capacitar os profissionais de saúde que atuam na área conforme recomendam as diretrizes referentes ao tema.

Nesse sentido, sugere-se a integração entre as Instituições de Ensino Superior, as empresas que utilizam serviços de motociclistas e os representantes das categorias profissionais envolvidas com esse tipo de transporte, a fim de ampliar a discussão e definir estratégias mais específicas de intervenção.

\section{Resumo}

No Brasil, observa-se um aumento dos acidentes envolvendo motocicletas. Este estudo objetivou caracterizar as vítimas desse tipo de acidente atendidas em um serviço de emergência no Piauí. Pesquisa quantitativa com amostra de 430 vítimas. A análise mostrou predominância do sexo masculino, na faixa etária de 15 a 24 anos e procedentes do próprio estado. Observou-se que 301 dessas vitimas eram condutores da motocicleta, 81 passageiros e 48 foram atropelados por moto. Verificou-se que $76,05 \%$ das vítimas sofreram acidente de quinta-feira a domingo, 80,75\% apresentaram seqüelas temporárias e 52,33\% dos acidentes ocorreram no período noturno. Os tipos de lesão corresponderam em
$69,3 \%$ dos casos a ferimentos; $51,4 \%$ a fraturas; $27,44 \%$ a hematomas; $e$ 20,7\% a traumatismos cranioencefálicos. Entre as vítimas de acidente, condutores da moto e suspeitos de ingestão de álcool, 52,07\% não utilizavam capacete no momento do acidente. A maioria das vítimas recebeu alta hospitalar e 14 foram a óbito. Conclui-se que o trauma provocado pelos acidentes envolvendo motocicletas merece atenção, especialmente em relação ao planejamento de ações preventivas, assim como controle de sua ocorrência no estado.

Acidentes de Trânsito; Motocicletas; Serviços Médicos de Emergência 


\section{Colaboradores}

A. M. R. Santos participou desde o planejamento até a análise dos dados e redação final. M. E. B. Moura contribuiu com o planejamento, a análise dos dados e a revisão crítica do manuscrito. B. M. V. T. Nunes auxiliou na fase de análise dos dados e na revisão final do artigo. C. F. S. Leal participou na coleta e análise dos dados da pesquisa. J. B. M. Teles participou no planejamento e análise estatística dos dados da pesquisa.

\section{Agradecimentos}

Agradecemos o financiamento à Fundação de Amparo à Pesquisa do Estado do Piauí (FAPEPI), em parceria com a Secretaria Estadual de Saúde do Piauí (SESAPI), ao Conselho Nacional de Desenvolvimento Científico e Tecnológico (CNPq) e ao Ministério da Saúde, por intermédio do Departamento de Ciência e Tecnologia (DECIT).

Agradecemos também aos alunos do Curso de Graduação em Enfermagem da Faculdade NOVAFAPI: Andréa Régia de Araújo Flor, Beatriz Evelim Carvalho, Cynara Ferreira Lopes, Hélida Lessa Cardoso Pereira, Raquel Vilanova Araújo e Tony Ângelo de Sousa Silva, pela contribuição na coleta de dados, e à Evanilda Fonseca por sua ajuda com o programa SPSS.

\section{Referências}

1. Jorge MHPM, Laurenti R. Apresentação. Rev Saúde Pública 1997; 31(4 Suppl):1-4.

2. Minayo MCS. A difícil e lenta entrada da violência na agenda do setor saúde. Cad Saúde Pública 2004; 20:646-7.

3. Minayo MCS. Implementação da Política Nacional de Redução de Acidentes e Violências. Cad Saúde Pública 2007; 23:4-5.

4. Oliveira NLB, Sousa RMC. Diagnóstico de lesões e qualidade de vida de motociclistas, vítimas de acidentes de trânsito. Rev Latinoam Enferm 2003; 11:749-56.

5. Portal do Trânsito. Os números do trânsito. http:// www.transito.hpg.ig.com.br/ (acessado em 30/ Mar/2005)

6. Departamento Estadual de Trânsito. Acidentes de trânsito com vítimas e sem vítimas registrados no estado em 2004. http://www.detran.pi.gov. br/download/Estatistica2004/ (acessado em 05/ Mar/2006)

7. Jorge MHPM. À guisa de conclusão. Rev Saúde Pública 1997; 31(4 Suppl):51-4.

8. Koizumi MS. Padrão das lesões nas vítimas de acidentes de motocicleta. Rev Saúde Pública 1992; 26:475-89.

9. Andrade SM, Soares DA, Braga GP, Moreira JH, Botelho FMN. Comportamentos de risco para acidentes de trânsito: um inquérito entre estudantes de medicina na região sul do Brasil. Rev Assoc Méd Bras 2003; 49:439-44.
10. Bastos YGL, Andrade SM, Soares DA. Características dos acidentes de trânsito e das vítimas atendidas em serviço pré-hospitalar em cidade do Sul do Brasil, 1997/2000. Cad Saúde Pública 2005; 21: 815-22.

11. Sauer MTN, Wagner MB. Acidentes de trânsito fatais e sua associação com a taxa de mortalidade infantil e adolescência. Cad Saúde Pública 2003; 19:1519-26.

12. Santos AMR, Coelho MJ. Atendimento de cliente com traumatismo em um serviço de emergência de hospital do Piauí. Esc Anna Nery Rev Enferm 2003; 7:369-78.

13. Governo do Estado do Piauí. Governo aprova projeto de educação para motociclistas. http://www. pi.gov.br/materia.php (acessado em 04/Set/2005).

14. Waksman RD, Pirito RMBK. O pediatra e a segurança no trânsito. J Pediatr 2005; 81(5 Suppl):81-8.

15. Faria EO, Braga MGC. Propostas para minimizar os riscos de acidentes de trânsito envolvendo crianças e adolescentes. Ciênc Saúde Coletiva 1999; 4:95-107.

16. Centers for Disease Control and Prevention. Nonfatal injuries from off-road motorcycle riding among children and teens - United States, 20012004. MMWR Morb Mortal Wkly Rep 2006; 55: 621-4.

17. Koizumi MS. Acidentes de motocicleta no Município de São Paulo, SP (Brasil): caracterização do acidente e da vítima. Rev Saúde Pública 1985; 19: 475-89. 
18. Veronese AM, Oliveira DLC. Os riscos dos acidentes de trânsito na perspectiva dos moto-boys: subsídios para a promoção da saúde. Cad Saúde Pública 2006; 22:2717-21.

19. Marín L, Queiroz MAS. A atualidade dos acidentes de trânsito na era da velocidade: uma visão geral. Cad Saúde Pública 2000; 16:7-21.

20. Pinsky I, Labouvieb E, Laranjeira R. Disposição e alternativas ao dirigir alcoolizado entre jovens paulistanos. Rev Bras Psiquiatr 2004; 26:234-41.

21. Marin-Leon L, Vizzotto MM. Comportamentos no trânsito: um estudo epidemiológico com estudantes universitários. Cad Saúde Pública 2003; 19: 515-23.

22. Conselho Nacional de Trânsito. Resolução nº 203. Disciplina o uso de capacete para condutor e passageiro de motocicleta, motoneta, ciclomotor, triciclo motorizados e quadriciclo motorizado, e dá outras providências. Diário Oficial da União 2006; 10 nov.

23. Associação Brasileira de Motociclistas. Segurança: os 12 mandamentos do motociclista. http:// abrambrasil.org.br/index.html (acessado em 02/ Fev/2007).

24. Bried JM, Cordasco FA, Volz RG. Medical and economic parameters of motorcycle-induced trauma. Clin Orthop Relat Res 1987; (223):252-6.
25. May C, Morabito D. Motorcycle helmet use, incidence of head injury, and cost of hospitalization. J Emerg Nurs 1989; 15:389-92.

26. Sarkar SMD, Peek C, Kraus JF. Fatal injuries in motorcycle riders according to helmet use. J Trauma 1995; 38:242-5.

27. Batista SEA, Baccani JG, Silva RAP, Gualda KPF Vianna Jr. RJA. Análise comparativa entre os mecanismos de trauma, as lesões e o perfil de gravidade das vítimas, em Catanduva - SP. Rev Col Bras Cir 2006; 33:6-10.

28. Deslandes SF, Silva CMFP, Ugá MAD. O custo do atendimento emergencial às vítimas de violências em dois hospitais do Rio de Janeiro. Cad Saúde Pública 1998; 14:287-99.

29. Ministério da Saúde. Política nacional de redução da morbimortalidade por acidentes e violências: portaria MS/GM no. 737 de 16/05/01. Diário Oficial da União 2001; 18 mai.

30. Vieira GO, Assis MMA, Nascimento MAA, Vieira TO, Santana Netto PV. Violência e mortes por causas externas. Rev Bras Enferm 2003; 56:48-51.

31. Reichenheim ME, Werneck GL. Anos potenciais de vida perdidos no Rio de Janeiro, 1990. As mortes violentas em questão. Cad Saúde Pública 1994; 10 Suppl 1:188-98.

Recebido em 09/Mar/2007

Versão final reapresentada em 10/Dez/2007

Aprovado em 14/Jan/2008 